\title{
Expression of CD44 and integrins in bronchial mucosa of normal and mildly asthmatic subjects
}

\author{
D.G. Peroni, R. Djukanović, P. Bradding, I.H. Feather, S. Montefort, \\ P.H. Howarth, D.B. Jones*, S.T. Holgate
}

Expression of CD44 and integrins in bronchial mucosa of normal and mildly asthmatic subjects. D.G. Peroni, R. Djukanović, P. Bradding, I.H. Feather, S. Montefort, P.H. Howarth, D.B. Jones, S.T. Holgate. CERS Journals Ltd 1996.

ABSTRACT: We have investigated the expression of cell surface markers and leucocyte cell adhesion molecules by immunohistochemistry in bronchial biopsies from 10 mild atopic asthmatics and 8 normal, nonatopic subjects.

Significantly increased numbers of eosinophils $(p<0.01)$ were evident in the bronchial submucosa of asthmatic subjects. In epithelium there were more CD44+ $(p<0.02)$ and lymphocyte function-associated antigen-1 (LFA-1)+ $(p<0.06)$ leucocytes in asthmatics than in normal subjects. Bronchial epithelial cells stained positively with anti-CD44 monoclonal antibodies (moAb) in both groups; however, when the staining was expressed as percentage of the total basement membrane, a considerable and highly significant increase was observed in the asthmatics (median 80 vs $22 \%, p=0.003$ ). Few leucocytes were positive for very late activation antigen (VLA)-1, VLA-2 and VLA-4. The moAb for VLA-6 stained the basement membrane of the bronchial epithelium; while intracellular adhesion molecule-1 (ICAM-1) and vascular cell adhesion molecule-1 (VCAM-1) were constitutively expressed in endothelium. A positive correlation was found between LFA-1+ cells and activated eosinophils $(E G 2+)$ in the submucosa $\left(p<0.005 ; r_{\mathrm{s}}=0.80\right)$.

We conclude that even in mild asthma there is evidence of increased expression of cell surface ligands, and suggest that adhesive mechanisms play a role both in cell recruitment and disease activity.

Eur Respir J., 1996, 9, 2236-2242.
Immunopharmacology Group, University Medicine and *Dept of Pathology, University of Southampton, UK

Correspondence: S.T. Holgate

University Medicine

Level D, Centre Block

Southampton General Hospital

Southampton SO16 6YD

UK

Keywords: Adhesion molecules asthma

CD44

eosinophils

Received: June 71995

Accepted after revision July 301996
There is accumulating pathological evidence to imply a role for chronic inflammation of the bronchial mucosa in determining both the physiological abnormalities and severity of atopic bronchial asthma [1-3]. In the process of accumulation of inflammatory cells in the inflamed mucosa, one of the primary steps is their infiltration into the tissue, a phenomenon which is mediated by specific interactions between cell surface molecules and their endothelial ligands [4]. The mechanisms of cell-cell and cell-matrix interactions involve increased expression of cell adhesion molecules (CAMs) on the cell and vessel surfaces [4]. Immunohistochemical studies of bronchial biopsies have shown constitutive expression of several CAMs, such as intercellular adhesion molecule-1 (ICAM1 ), a member of the immunoglobulin supergene family, and E-selectin. a member of the selectin family [5]. In support of the role for CAMs in allergic inflammation, studies in monkeys have shown that allergen challenge in Ascaris suum-sensitized animals results in upregulation of ICAM-1 in parallel with an increase in bronchial responsiveness, both of which can be abrogated by pretreatment with blocking anti-ICAM-1 antibodies [6]. Studies in mild asthma have shown that the expression of ICAM-1 and E-selectin is not different from that in healthy, nonatopic control subjects [5]; however, in perennial rhinitis, where chronic inflammation may be more severe, both ICAM-1 and the vascular cell adhesion molecule-1 (VCAM-1) have been found to be upregulated [7]. Furthermore, following local allergen challenge the number of mucosal blood vessels staining positively with antibodies directed against ICAM-1 and E-selectin increases severalfold [8]. When considered together with the associated increase in inflammatory cells expressing the lymphocyte function associated antigen-1 (LFA-1), an integrin which acts as the ligand for ICAM-1, these observations clearly implicate adhesive mechanisms in cell recruitment into asthmatic bronchial tissues [8].

Recently, studies of lymphocyte activation and cellcell and cell-matrix adhesion have converged on a broadly distributed human cell surface glycoprotein known as CD44 or Hermes antigen [9]. The CD44 molecule demonstrates marked structural differences between tissues, due to alternative splicing and variable glycosylation. Although the standard form, containing no variant regions, is expressed on lymphocytes, CD44 isoforms have been shown by complementary deoxyribonucleic acid (cDNA) cloning and sequencing to be weakly expressed in the normal epithelium and highly expressed in some metastatic carcinomas, such as adenocarcinomas, and on aggressive types of non-Hodgkin's lymphoma [10]. The CD44 binds to hyaluronic acid and is involved in 
the heterotypic recognition of high endothelial venules (HEV), the specialized venules in lymphoid tissue that mediate lymphocyte extravasation in the process of lymphocyte homing [9].

In order to further evaluate the distribution and possible role of adhesive molecules in allergic inflammation, we have analysed the expression of CAMs in bronchial biopsies obtained from atopic mild-to-moderate asthmatic patients and healthy nonatopic control subjects using immunohistochemistry. We have investigated the expression of ICAM-1 and its ligand, LFA-1 and VCAM1 and its ligand, very late activation antigen (VLA)-4, adhesion molecules for which a role in asthma pathogenesis has been strongly suggested $[7,8]$. We have extended the study of very late antigens to VLA-1 and VLA-2 as markers of T-cell activation, since it has been shown that VLA-1 is upregulated in acute exacerbations of asthma [11], and also VLA-6, which is involved with the $\alpha_{6}$-chain in the specific adhesive mechanisms in the bronchial epithelium [12]. Because nothing is known about the contribution, if any, of CD44 to asthma pathogenesis, we have studied the distribution of cells staining positively for this adhesion molecule and its expression on the surface of epithelial cells.

To provide correlates between adhesion molecules and inflammatory cell types, we have enumerated mast cells, activated eosinophils and CD3+ lymphocytes, and have related the cell counts to the level of expression of CAMs.

\section{Materials and methods}

\section{Subjects}

Ten patients with mild to moderately severe asthma ( 5 females and 5 males; mean age 30 yrs, range 21-49 yrs) and eight normal nonatopic control subjects (2 females and 6 males; mean age 29 yrs, range $18-59$ yrs) were recruited into the study. All the asthmatics had stable pulmonary function, with a forced expiratory volume in one second (FEV1) $\geq 70 \%$ of predicted. The median FEV1 was $88 \%$ (range $74-108 \%$ ) for asthmatics and 96\% (range $82-112 \%$ ) for the normal subjects. All the asthmatics were atopic as confirmed by skin prick testing with a series of common inhalant allergens (Dermatophagoides pteronyssinus, mixed grass pollen, cat fur, dog hair, feathers, and a mixture of moulds; Bencard, Brentford, UK). The asthmatics had mild-to-moderate airways responsiveness as assessed by the provocative concentration of inhaled methacholine required to produce a $20 \%$ fall in FEV1 (PC20) (geometric mean $\mathrm{PC} 202.82$, range 0.11$\left.25 \mathrm{mg} \cdot \mathrm{mL}^{-1}\right)$ [13]. In none of the normal control subjects was it possible to induce a fall $\geq 20 \%$ in FEV1 with the highest concentration of methacholine used (25 $\left.\mathrm{mg} \cdot \mathrm{mL}^{-1}\right)$. All the asthmatics used the $\beta_{2}$-agonist salbutamol as required for relief of symptoms. None of the asthmatics had received any treatment with oral or inhaled corticosteroids, sodium cromoglycate or nedocromil sodium for at least three months prior to bronchoscopy. All the subjects were nonsmokers and none had experienced an upper respiratory tract infection within 6 weeks of the study. The healthy volunteers had no history of asthma, were on no medication, and all had negative skin prick tests to the same range of allergens.

The study was approved by the combined Southampton Hospitals and University Ethics Committee and all the participants gave their written informed consent.

\section{Bronchoscopy}

All the procedures were performed using a fibreoptic bronchoscope (Olympus 1T20, Tokyo, Japan) according to the National Institute of Health guidelines [14], and as reported previously [15].

\section{Monoclonal antibodies}

The following mouse antibodies were used: 1) antiLFA-1 moAb, clone TS1-22 (a gift from T.A. Springer, Boston, MA, USA); 2) anti-CD44 moAb, clone Hermes 3 (a gift from S. Jalkanen, Turku, Finland); 3) antiVLA-1 moAb, clone TS2/7 (a gift from T.A. Springer, Boston, MA, USA); 4) anti-VLA-2 moAb, clone CLB ThIV (a gift from the Netherland Red Cross, Amsterdam); 5) anti-VLA-4 moAb, clone CLB 485 (Cymbus Ltd, Southampton, UK) and anti-VLA-4 moAb, clone HP1/2 (provided by R. Lobb, Biogen Ltd, Boston, MA, USA); 6 ) the clone GOH-3 against the $\alpha_{6}$-chain of the human VLA-6 heterodimer $\left(\alpha_{6} \beta_{1}\right)$ (a gift from A. Sonnenberg, The Netherlands); 7) anti-ICAM-1 moAb, clone RRI (a gift from R. Rothlein, USA); 8) anti-VCAM-1 moAb, clone 1.4C3 (a gift from D. Haskard, London, UK); 9) antiendothelium moAb, clone EN4 (San Bio, Netherlands); (10) anti-mast cell tryptase moAb, clone AA1 (a gift from A. Walls, Southampton, UK); 11) anti-eosinophil cationic protein moAb, clone EG2; and 12) anti-CD3 moAb (Dako Ltd, High Wycombe, UK).

\section{Processing of samples}

The biopsy samples were processed into glycol methacrylate resin (GMA) (Polysciences, Northampton, UK) and stored in airtight containers at $-20^{\circ} \mathrm{C}$ [16]. The GMA sections were cut $2 \mu \mathrm{m}$ thick and two sections per moAb were picked onto poly-L-lysine glass slides. The moAb binding was displayed by peroxidase-labelled avidinbiotin complexes, as described previously [15]. The stained slides were coded and examined using a Leitz Ortholux 2 microscope by one observer (DGP), who was not involved in the patient care or biopsy procedure. In each biopsy, the moAb positive cells were counted separately in the epithelium and in the submucosa. The results were expressed as the number of cells per millimetre of basement membrane in the epithelium and per millimetre squared of submucosa in the subepithelial tissue. The area of the submucosa was calculated by delineating the area of the submucosa excluding the glands and blood vessels on a Video Interactive Display System (VIDS 2) and using AMS software (Analytical Measurement Systems, Cambridge, UK). 
The expression of cell adhesion molecules in the endothelium was evaluated as described previously [7]. In order to evaluate the accurate localisation of immunoreactivity, sequential $2 \mu \mathrm{m}$ sections were obtained. One section was stained for the presence of an endothelial cell adhesion molecule and the adjacent section stained with a vessel marker, EN4, to identify all the blood vessels in the sections. The numbers of vessels stained positively for the two adhesion molecules, ICAM-1 and VCAM-1, in consecutive sections were expressed as a percentage of the total number of vessels. Positive staining for any of the adhesion molecules in the epithelium and basement membrane (bm) was expressed as a percentage of their total length.

\section{Statistical analysis}

All the immunohistochemical data are shown as median and range. The Mann-Whitney U-test was used to analyse differences between groups in cell counts and CAM expression. The Spearman's rank coefficient was used to investigate the relationship between the expression of adhesion molecules and leucocyte phenotypes.

\section{Leucocyte phenotypes}

Results

The median (range) numbers of mast cells, identified as AA1+ cells in the epithelium were $0.1(0-2.4)$ cells. $\mathrm{mm}^{-1} \mathrm{bm}$ in the asthmatics and $0.25(0-2.0)$ cells $\cdot \mathrm{mm}^{-1}$ $\mathrm{bm}$ in the normal subjects $(\mathrm{p}>0.05)$. There were 54.5 (0.9-150.0) AA1 cells $\cdot \mathrm{mm}^{-2}$ of submucosa ( $\mathrm{sm}$ ) and 55.7 (22.9-64.7) cells $\cdot \mathrm{mm}^{-2} \mathrm{sm}$, in the asthmatics and normal subjects, respectively, with no significant difference existing between the two groups. When staining for eosinophils with moAb EG2, which identifies "activated" cells, a significant difference $(\mathrm{p}<0.01)$ was observed between the asthmatic patients (13.1 (4.1-195.2) cells $\left.\cdot \mathrm{mm}^{-2} \mathrm{sm}\right)$ and normal subjects $(2.6(0-16.1)$ cells. $\mathrm{mm}^{-2} \mathrm{sm}$ ) in the bronchial submucosa (fig. 1), but not in the epithelium $\left(0.16(0-1.6)\right.$ and 0 cells $\cdot \mathrm{mm}^{-1} \mathrm{bm}$, respectively). There was no difference in the number of CD3+ T-lymphocytes between the asthmatic patients and normal subjects both in the epithelium (3.2 (0-26.6) vs $5.5(0-13.3)$ cells $\left.\cdot \mathrm{mm}^{-1} \mathrm{bm}\right)$, and submucosa $(231.8$ (10.5-650.0) vs $106.4(57.8-276.8)$ cells $\left.\cdot \mathrm{mm}^{-2} \mathrm{sm}\right)$ (fig. $1)$.

\section{Expression of adhesion molecules}

In the epithelium of asthmatics, there were significantly $(\mathrm{p}<0.02)$ more leucocytes staining for CD44 than in the normal controls (29.3 (5.9-94.3) and $6.6(0-33.8)$ cells $\cdot \mathrm{mm}^{-1} \mathrm{bm}$, respectively) (fig. $2 \mathrm{a}$ ). The CD44+ cells were identified, according to their morphology, as lymphocytes, macrophages and eosinophils. In the submucosa, no difference was observed for CD44+ leucocytes between the asthmatics (45.7 (24.1-87.0) cells $\left.\cdot \mathrm{mm}^{-2} \mathrm{sm}\right)$ and control subjects (36.0 (4.1-92.0) cells $\left.\cdot \mathrm{mm}^{-2} \mathrm{sm}\right)$ (fig. 2b). CD44+ staining was also present on bronchial epithelial cells in both groups, localized predominantly

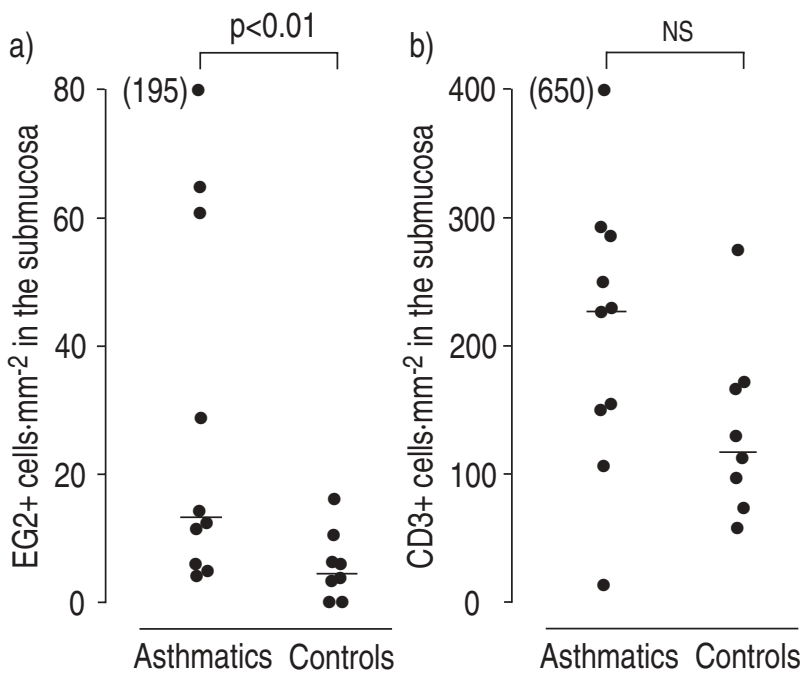

Fig. 1. - Numbers of: a) submucosal EG2+ activated eosinophils; and b) CD3+ cells in the submucosa in asthmatics and control (normal) subjects. Horizontal lines denote median values. NS: statistically nonsignificant.
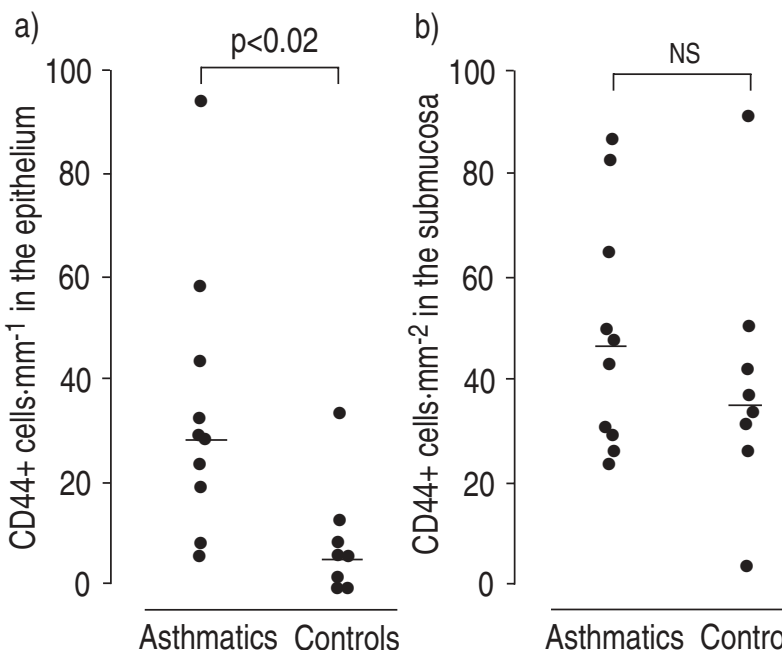

Fig. 2. - Numbers of CD44+ cells: a) in the epithelium; and b) in submucosa in asthmatics and control subjects. Horizontal lines denote median values. NS: statistically nonsignificant.

around the apical and lateral sides of the basal cells, although staining was also noted among the columnar cells and between the basal cells and the basement membrane (fig. 3). When the CD44 staining between the basal cells and the basement membrane (expressed as the percentage of the length of the epithelium) was compared between groups, a highly significant difference was seen, with a median $80 \%$ (range $28-100 \%$ ) of the bronchial epithelium staining positively in the asthmatics compared to $22 \%$ (range $0-36 \%)$ in the controls $(\mathrm{p}=0.003)$ (fig. 4).

In the asthmatic group, the LFA-1+ leucocytes in the epithelium $\left(10.8(0-34.1)\right.$ cells $\left.\cdot \mathrm{mm}^{-1} \mathrm{bm}\right)$ were increased by comparison with the normal subjects (3.35 (1.3714.5) cells $\left.\cdot \mathrm{mm}^{-1} \mathrm{bm}\right)$, but this just failed to reach statistical significance ( $\mathrm{p}=0.06$ ) (fig. 5a). No difference was observed in the number of LFA-1+ cells in the submucosa between the asthmatics $\left(33.0(10.9-101.2)\right.$ cells $\cdot \mathrm{mm}^{-2}$ $\mathrm{sm})$ and controls (34.0 (2.0-57.9) cells $\left.\mathrm{mm}^{-2} \mathrm{sm}\right)$ (fig. 5b). 


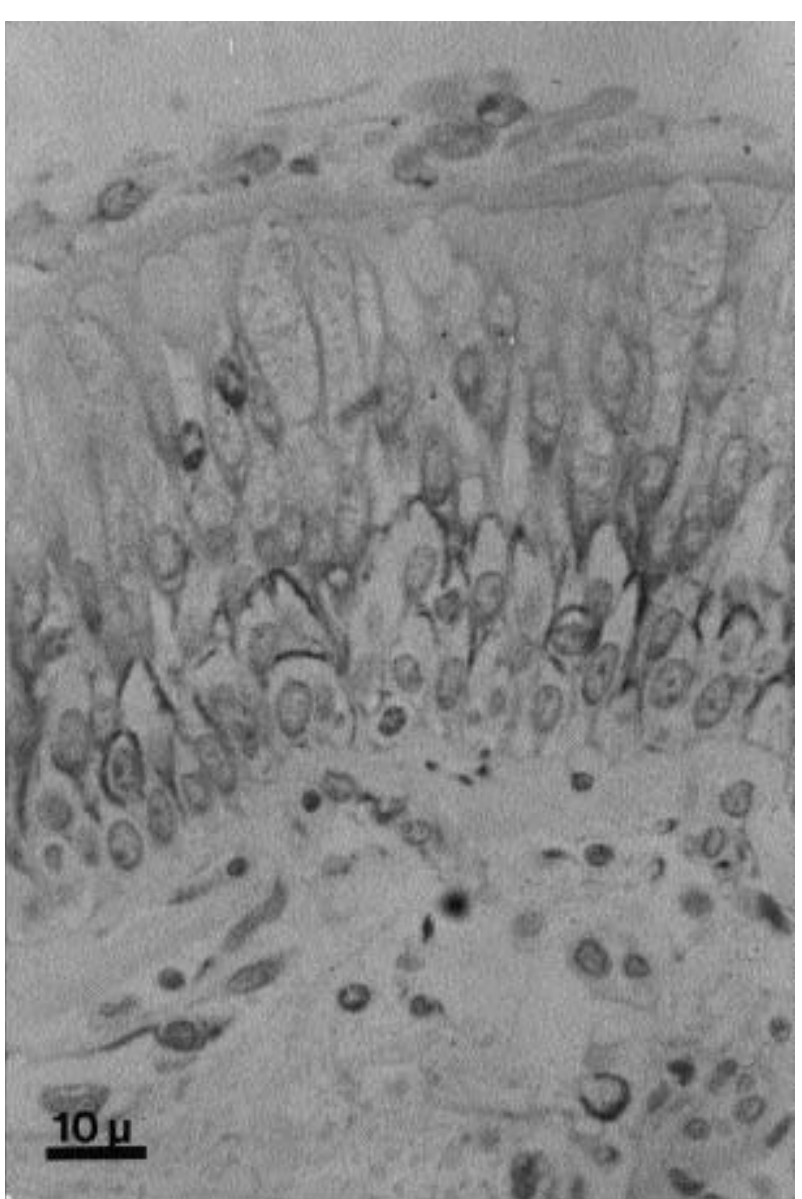

Fig. 3. - Light microscopic micrograph of a bronchial biopsy taken from an asthmatic subject, embedded in glycol methacrylate and immunostained with monoclonal antibody (moAb) to CD44. Internal scale bar $=10 \mu \mathrm{m}$.

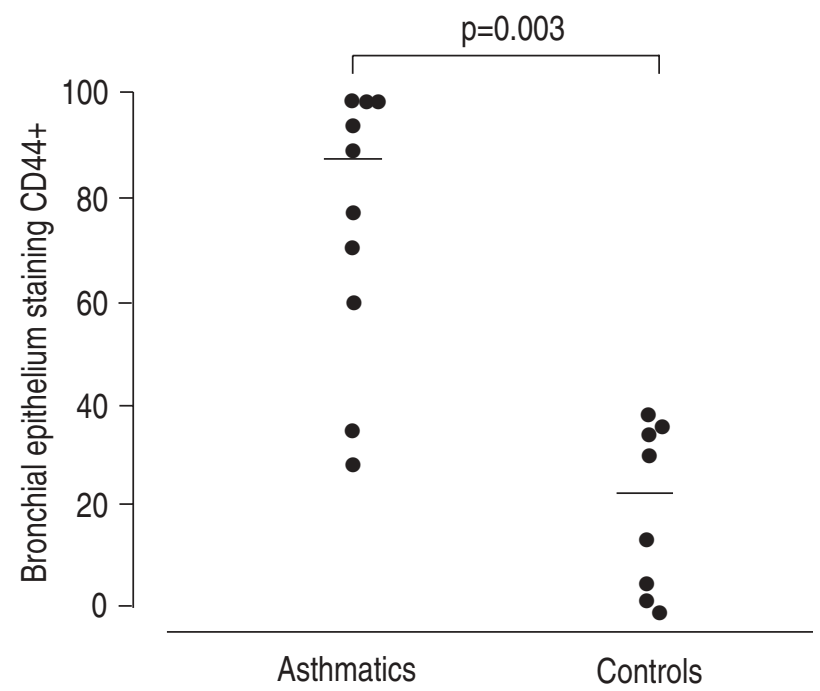

Fig. 4. - Percentages of bronchial epithelium staining for CD44 in asthmatics and control (normal) subjects. Horizontal lines denote median values.

Few cells stained positively for the very late antigens. In the epithelium, no positive cells were observed when moAbs anti-VLA-1 and anti-VLA-2 were used. In the submucosa, a few cells stained positively for VLA-1 and VLA-2 both in the asthmatics (2.1 (0-4.3) and $0(0-3.4)$ cells $\left.\cdot \mathrm{mm}^{-2} \mathrm{sm}\right)$, respectively) and normal a)

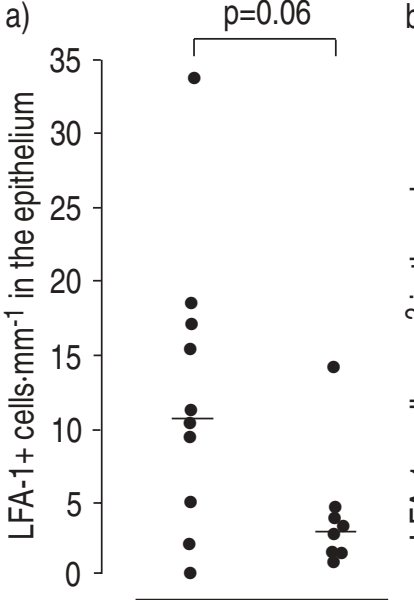

Asthmatics Controls b)

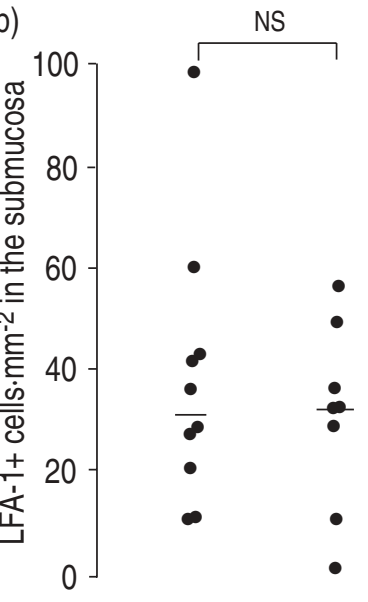

Asthmatics Controls
Fig. 5. - Numbers of lymphocyte function-associated antigen-1 (LFA-1)+ leucocytes in the epithelium; and b) the submucosa in asthmatics and control (normal) subjects. Horizontal lines denote median values. NS: statistically nonsignificant.

subjects $\left(0.7(0-0.25)\right.$ and $0(0-0.8)$ cells $\left.\cdot \mathrm{mm}^{-2} \mathrm{sm}\right)(\mathrm{p}>$ $0.05)$. No statistical difference was observed between the asthmatic and normal subjects in the number of VLA-4 cells, both in the epithelium $(0$ (0-1.5) vs 0.6 $(0-4.6)$ cells $\left.\cdot \mathrm{mm}^{-2} \mathrm{bm}\right)$ and submucosa $(3.8(0-10.0)$ vs $1.3(0-10.8)$ cells $\left.\cdot \mathrm{mm}^{-2} \mathrm{sm}\right)$.

Using moAbs against VLA-4 from two sources, no positive staining for the chain of VLA-4 was observed in the basement membrane of the epithelium or blood vessels. Although no VLA-6 positive staining of inflammatory or structural cells was seen, in both groups the distribution of $\alpha_{6}$-chain was localized to the zone between the basal cell layer and the basement membrane, and in the wall of some vessels of the bronchial submucosa.

Staining for ICAM-1 was expressed constitutively in the microvascular endothelium both of the asthmatic (median $24 \%$ of blood vessels, range $0-69 \%$ ) and normal biopsies (median $25 \%$ of blood vessels, range 0 $100 \%)(\mathrm{p}>0.05)$. VCAM-1 was expressed at a very low level in all biopsies (median $0 \%$ of blood vessels (range $0-5 \%$ ) in the asthmatics, and $0 \%$ of blood vessels range $(0-3 \%)$ in the control group).

Relationship between adhesion molecule expression, leucocyte phenotypes and clinical activity

When the expression of adhesion molecules was compared with the number of leucocytes present in the bronchial mucosa, a strongly positive correlation was observed between LFA-1+ cells and EG2+ staining eosinophils in the submucosa $\left(r_{\mathrm{s}}=0.80 ; \mathrm{p}<0.005\right)$. No other correlations between the expression of the different adhesion molecules and infiltrating cell type was found. No correlation was observed between the adhesion data and the severity of disease activity.

\section{Discussion}

Using fibreoptic bronchoscopy to obtain bronchial biopsies, and immunohistochemistry, we have studied the leucocyte phenotypes and expression of CAMs in the 
bronchial mucosa of atopic asthmatic and nonatopic control subjects. As reported previously, a prominent eosinophilia was seen in the bronchial mucosa of asthmatics $[15,17]$, although no differences in the counts of lymphocytes and mast cells were observed [18]. Immunohistochemical staining showed constitutive expression of all the adhesion molecules studied, except for VLA-6 on inflammatory cells. Whilst there was relatively abundant staining for LFA-1, which was higher in the asthmatics in the epithelium, only a few cells stained for VLA-1, VLA-2 and VLA-4, with no difference between asthmatics and normals. Staining for GOH-3 moAb, recognizing the $\alpha_{6}$-chain of the integrins $\alpha_{6} \beta_{1}$ (VLA6 ) and $\alpha_{6} \beta_{4}$, was strongly displayed on the basement membrane and basal layers of the epithelium, a finding which is in keeping with the previous localization of integrin $\alpha_{6} \beta_{4}$ to hemidesmosomes [19-21].

Increased staining for the homing antigen, CD44, was observed on leucocytes in the bronchial epithelium and on epithelial cells of the asthmatic subjects. In keeping with previous reports [22], and demonstrated by using antibodies from different sources, we found no staining for VLA-4 in the basement membrane of either the epithelium or blood vessels. Basal expression of ICAM-1 and VCAM-1 on postcapillary venules was noted, although no difference was seen between asthmatics and control subjects.

Although the number of cells staining for anti-LFA-1 was higher in the epithelium of asthmatic subjects, this just failed to reach significance, possibly due to the mild disease activity of the asthmatics studied. A positive correlation between LFA-1+ staining and the number of EG2+ eosinophils was observed, suggesting that in asthmatics LFA-1 may be contributing to the migration of activated eosinophils into the airways mucosa. In the asthmatic biopsies of the present study there was a very large number of CD3+ lymphocytes in submucosa but very few cells positive for LFA-1, that is thought to be expressed on all leucocytes. A possible explanation could be the different status of activation of the CD3+ cells, since it is well recognized that the CD45RO+ T-lymphocyte subpopulation, which exhibits antigen recall, has a greater constitutive expression of LFA-1 than do naive T-cells (CD45RA+) [23], and lymphocyte activation is known to upregulate LFA-1 expression [24].

The CD44 antigen, originally identified as the lymphocyte homing receptor and termed Hermes antigen, has been shown to be responsible for binding of lymphocytes to hyaluronic acid [9]. The moAb used in this study, Hermes-3, was produced by immunization with affinity isolated antigen from mucosal-specific cells and recognizes the same glycoprotein defined by Hermes1. It inhibits lymphocyte binding to mucosal HEVs and not to lymph node or synovial HEVs [9]. More recently, CD44 distribution has been extended to nonlymphoid tissue, such as fibroblasts, smooth muscle cells and the bronchial and alveolar epithelium [25]. The role of this molecule is still debated: it is thought to be involved in several steps of normal immune cell function, such as lymphocyte adhesion to HEV [26] and the extracellular matrix, as well as in T-cell activation [27]. It has been shown that triggering of CD44 on T-lymphocytes by anti-CD44 moAb can promote cell adhesion via the LFA-1 pathway [28], and induce resting peripheral blood lymphocytes to proliferate in the presence of phorbol esters [29]. The CD44+ leucocytes were identified as lymphocytes, macrophages and eosinophils according to their morphology. However, these observations were sustained by the use, in some specimens, of camera lucida technique, which makes it possible to identify cell localization using two moAbs in adjacent sections of the biopsy [16].

The bronchial epithelium also showed strong expression of CD44, which was at a significantly higher level in the asthmatics than controls. The staining was distributed around the periphery of the bronchial epithelial cells both in normal subjects and asthmatics. Unlike the other markers, CD44 was also expressed as a percentage staining per millimetre of basement membrane; the CD44 epithelial cell staining was strong and diffuse between the basal cells and the basal membrane. Most recently, we have utilized immunoelectronmicroscopy to quantify CD44 expression in the bronchial epithelium of normal and asthmatic subjects, and have confirmed an asthma-related upregulation [30]. The diffuse presence of CD44 in the normal epithelium suggests that this glycoprotein is involved in the normal adhesion between structural cells, but its upregulation on inflammatory cells and in the epithelium in asthma indicates a possible role in cell recruitment and in epithelial repair. The much broader tissue distribution of CD44 suggests that it promotes a type of adhesion which is exploited by a wide variety of cells [10].

As we have reported previously, ICAM-1 was present constitutively in about $30 \%$ of the postcapillary venules of the airways mucosa [5], and the distribution in asthmatic subjects was not different from that in nonatopic control subjects [5], a finding that may be explained by the mild disease of the subjects studied.

The family of integrins represents a group of transmembrane glycoprotein receptors, consisting of noncovalently associated $\alpha$ and $\beta$ subunits [4, 19, 22]. Although several studies have investigated the expression of integrins in cell cultures [19, 22], little is known about their distribution in diseased lung tissue [31], and it remains unclear to what extent the integrins are crucial to the allergic inflammation in atopic asthma. The $\beta_{2}$-integrin LFA-1 (CD11a/CD18), which is the leucocyte ligand for ICAM-1, was expressed on more cells in the asthmatics than in control subject but, possibly because most of the subjects experienced only mild-tomoderate asthma, the increase in LFA-1+ leucocytes just failed to reach significance. We have previously found an increase in LFA-1+ staining cells in the airway wall after local allergen challenge in asthmatics with disease activity that was comparable to that of the subjects in the present study [8]. Since LFA-1 is expressed on almost all leucocytes, it is considered to be an index of the total number of infiltrating inflammatory cells. Thus, the increased number of LFA-1+ cells in the present study reflects a general increase in leucocytes. This heterodimer plays a role in leucocyte-leucocyte interaction and leucocyte-endothelial cell adhesion. In addition, LFA-1 expression is upregulated on activated lymphocytes [24]. The number of cells staining positively for this adhesion molecule has also been found to be elevated in perennial rhinitis and to correlate with the degree of neutrophil infiltration [7]. In the present 
study, we have found a positive correlation between LFA-1 and the number of activated eosinophils, a finding which is in keeping with the eosinophilic nature of the cellular infiltrate in the lower airways in asthma.

Very few cells stained for VLA-4, the ligand for VCAM-1. In order to reduce any doubt on the sensitivity of our method, we used antibodies from two different sources; however, immunostaining of cells was low with both the moAbs used, even if the EG2+ and CD3+ cell counts were high. The same remark extends to VLA-6 and eosinophils in the submucosa. However the mechanism for eosinophil and lymphocyte recruitment in asthmatic airways involves a number of overlapping steps. A previous study by our group [8] suggested an upregulation of E-selectin and ICAM-1 but not VCAM-1 (the VLA-4 ligand) after allergen challenge. However, it is likely that the extent of VCAM-1 expression is too low to be detected by simple immunohistochemistry when compared to the marked upregulation of E-selectin and ICAM-1 that occurs in the presence of cytokines that regulate these adhesion molecules [32]. In keeping with previous reports, immunostaining for the integrins VLA1 and VLA-2 identified very few positive cells, and no cellular staining for VLA-6 [31]. Staining for integrin $\alpha_{6} \beta_{4}$, a component of hemidesmosomes, was localized to the basement membrane of the epithelium and submucosal vessels, as described previously in the cornea and skin [33, 34]. In acute exacerbations of asthma, VLA-1 has been shown to be upregulated on peripheral blood T-cells [11], and the low expression of these integrins in the mucosa in the present study is probably the consequence of the mild disease activity.

In conclusion, this study has provided evidence for the constitutive expression of several adhesion molecules in the epithelium and submucosa of normal airways, and upregulation of CD44 and LFA-1 in the bronchial mucosa in mild asthma suggestive of their role in facilitating leucocyte recruitment and activation. The observation of staining for CD44 in extracellular sites is novel and clearly requires further elucidation.

Our data show that in this study population of atopic patients with mild asthma there were more eosinophils and other leucocytes than in the controls, rather than an increased expression of the ligands. Further studies are necessary to obtain specimens from patients with severe asthma in order to verify whether the staining for CD11a and $\beta_{1}$-integrins will be expressed more strongly and to investigate alternative adhesive mechanisms on the leucocytes.

\section{References}

1. Dunnil MS. The pathology of asthma with special reference to changes in the bronchial mucosa. J Clin Pathol 1960; 13: 27-33.

2. Kay AB. Asthma and inflammation. J Allergy Clin Immunol 1991; 87: 893-899.

3. Djukanović R, Roche WR, Wilson JW, et al. Mucosal inflammation in asthma. Am Rev Respir Dis 1990; 142: 434-457.

4. Springer TS. Adhesion receptors of the immune system. Nature 1990; 346: 425-434.

5. Montefort S, Roche WR, Howarth PH, et al. Intercellular adhesion molecule-1 (ICAM-1) and endothelial leukocyte adhesion molecule-1 (ELAM-1) expression in the bronchial mucosa of normal and asthmatic subjects. Eur Respir $J$ 1992; 5: 815-823.

6. Wegner CD, Gundel RH, Reilly P, Haynes N, Gordon Letts L, Rothlein R. ICAM-1 in the pathogenesis of asthma. Science 1990; 247: 416-418.

7. Montefort S, Feather I, Wilson SJ, Howarth PH, Holgate ST. The expression of leukocyte-endothelial adhesion molecules is increased in perennial allergic rhinitis. Am J Respir Cell Mol Biol 1992; 7: 393-398.

8. Montefort S, Gratziou C, Goulding D, et al. Bronchial biopsy evidence for leukocyte infiltration and upregulation of leukocyte-endothelial cell adhesion molecules 6 hours after local allergen challenge of sensitised asthmatic airways. J Clin Invest 1994; 93: 1411-1421.

9. Jalkanen S, Jalkanen M, Bargatze M, Tammi M, Butcher EC. Biochemical properties of glycoproteins involved in lymphocyte recognition of high endothelial venules in man. J Immunol 1988; 141: 1615-1623.

10. Stamenkovic I, Aruffo A, Amiot M, Seed B. The hematopoietic and epithelial forms of CD44 are distinct polypeptides with different adhesion potentials for hyaluronate-bearing cells. EMBO J 1991; 10: 343-348.

11. Corrigan CJ, Hartnell A, Kay AB. T-lymphocytes activation in acute severe asthma. Lancet 1988; i: 11291131.

12. Roche WR, Montefort S, Baker J, Holgate ST. Cell adhesion molecules and the bronchial epithelium. Am Rev Respir Dis 1993; 148: S79-S82.

13. Chai H, Fan RS, Frolish LA, et al. Standardization of bronchial inhalation challenge procedures. J Allergy Clin Immunol 1975; 56: 323-327.

14. National Heart, Lung and Blood Institute Workshop Summaries. Summary and recommendations of a workshop on the investigative use of fiberoptic bronchoscopy and bronchoalveolar lavage in asthmatics. Am Rev Respir Dis 1985; 132: 180-182.

15. Djukanovic R, Wilson JW, Britten KM, et al. Quantitation of mast cells and eosinophils in the bronchial mucosa of symptomatic atopic asthmatics and healthy control subjects using immunohistochemistry. Am Rev Respir Dis 1990; 142: 863-871.

16. Bradding $\mathrm{P}$, Feather I, Howarth $\mathrm{P}$, et al. Interleukin-4 is localised to and released by human mast cells. $J$ Exp Med 1992; 176: 1381-1386.

17. Beasley R, Roche WR, Roberts JA, Holgate ST. Cellular events in the bronchi in mild asthma and after bronchial provocation. Am Rev Respir Dis 1989; 139: 806-817.

18. Bradley BL, Azawi M, Jacobson M, et al. Eosinophils, T-lymphocytes, mast cells, neutrophils and macrophages in bronchial biopsy specimens from atopic subjects with asthma: comparison with biopsy specimens from atopic subjects without asthma and normal control subjects and relationship to bronchial hyperresponsiveness. $J$ Allergy Clin Immunol 1991; 88: 661-674.

19. Albelda SM, Buck CA. Integrins and other cell adhesion molecules. FASEB J 1990; 4: 2868-2880.

20. Montefort S, Herbert CA, Robinson C, Holgate ST. The bronchial epithelium as a target for inflammatory attack in asthma. Clin Exp Allergy 1992; 22: 511-520.

21. Montefort S, Baker J, Roche WR, Holgate ST. The distribution of adhesive mechanisms in the normal bronchial epithelium. Eur Respir J 1993; 6: 1257-1263.

22. Albelda SM. Endothelial and epithelial cell adhesion molecules. Am J Respir Cell Mol Biol 1991; 4: 195-203.

23. Sanders ME, Makgoba W, Sharrow SO. Human memory T-lymphocytes express increased levels of three cell 
adhesion molecules and have enhanced IFN production. J Immunol 1988; 140: 1401-1407.

24. Van Kooyk YP, Van deWeil-van Kemenade P, Weder P, Kuijps TW, Figdor CD. Enhancement of LFA-1 mediated cell-adhesion by triggering through $\mathrm{CD} 2$ or CD3 on T-lymphocytes. Nature 1989; 342: 811-813.

25. Picker LJ, Nakache M, Butcher EC. Monoclonal antibodies to human lymphocyte homing receptors define a novel class of adhesion molecules on diverse cell types. J Cell Biol 1989; 109: 927-937.

26. Jalkanen ST, Bargatze RF, Herron L, Butcher EC. A lymphoid cell surface glycoprotein involved in endothelial cell recognition and lymphocyte homing in man. Eur J Immunol 1986; 16: 1195-1202.

27. Denning SM, Singer KH, Haynes BF. Antibodies against the CD44 p80, lymphocyte homing receptor molecule augment human peripheral blood T-cell activation. $J$ Immunol 1990; 144: 7-15.

28. Koopman G, Van Kooyk Y, De Graaff M. Triggering of the CD44 antigen on T-lymphocytes promotes T-cell adhesion through the LFA-1 pathway. J Immunol 1990; 145: 3589-3593.
29. Pierres A, Lipcey C, Mawas C, Olive D. A unique CD44 monoclonal antibody identifies a new T-cell activation pathway. Eur J Immunol 1992; 22: 413-417.

30. Lackie PM, Baker JE, Günthert U, Holgate ST. Expression of CD44 isoforms is increased in the airway epithelium of asthmatic subjects. Am J Respir Cell Mol Biol (in press)

31. Damjanovich L, Albelda SM, Mette SA. Buck CA. Distribution of integrin cell adhesion receptors in normal and malignant lung tissue. Am J Respir Cell Mol Biol 1992; 6: 197-206.

32. Bevilacqua MP, Stengelin PS, Gimbrone MA, Seed B. ELAM-1: an inducible receptor for neutrophils related to complement regulatory proteins and lectins. Science 1989; 243: 1160-1164.

33. Sonnenberg A, Calafat J, Jannsen H, et al. Integrin $\alpha_{6} \beta_{4}$ complex is located in hemidesmosomes, suggesting a major role in epidermal cell basement membrane adhesion. J Cell Biol 1991; 113: 907-917.

34. Stepp MA, Spurr-Michaud S, Tisdale A, Elwell J, Gipson IK. $\alpha_{6} \beta_{4}$ integrin heterodimer is a component of hemidesmosomes. Proc Natl Acad Sci USA 1990; 87: 897-906. 